\title{
Knowledge, attitude and practice towards COVID-19 among individuals with associated comorbidities
}

\author{
Shazina Saeed ${ }^{1 *}$, Aanchal Anant Awasthi ${ }^{2}$, Dhruv Nandi ${ }^{1}$, Karunanidhi Kaur ${ }^{1}$, Shamimul Hasan ${ }^{3}$, Rajiv Janardhanan ${ }^{2}$
}

\section{Author Affiliations:}

1. Laboratory of Disease Dynamics and Molecular Epidemiology, Amity Institute of Public Health, Amity University, Uttar Pradesh, Noida, India

2. Health Data Analytics and Visualization Environment Laboratory, Amity Institute of Public Health, Amity University, Uttar Pradesh, Noida, India

3. Department of Oral Medicine and Radiology, Faculty of Dentistry, Jamia Millia Islamia, New Delhi, India

\author{
* Corresponding Author: \\ Dr. Shazina Saeed, \\ Laboratory of Disease \\ Dynamics and Molecular \\ Epidemiology, Amity \\ Institute of Public Health, \\ Amity University, Uttar \\ Pradesh, Noida, India. \\ E-mail: ssaeed@amity.edu \\ DOI \\ 10.25122/jml-2020-0184
}

Dates

Received: 2 December 2020 Accepted: 15 March 2021

\begin{abstract}
The recent outbreak of coronavirus disease 2019 (COVID-19) is the worst global crisis after World War II. Since the vaccine trials are still ongoing, the national lockdowns have been the most effective way to contain its spread. The pandemic has been extremely stressful and full of anxiety for those with comorbidities as they are the most vulnerable to the COVID-19 infections. Various efforts to assess and enhance the knowledge, attitudes, and practice, especially the high-risk groups, are critical to managing the COVID-19 pandemic successfully. A cross-sectional online survey was carried out using a self-designed questionnaire. A total of 383 participants who were 30 years or older, with at least one comorbidity, were included in the study. The mean age of the participants was $50.63 \pm 11.83$ years. The most common comorbidities among the included participants were hypertension, followed by diabetes mellitus and thyroid disorders $(48.5 \%, 44.7 \%$ and $23.3 \%$, respectively). Our study also showed the education $(\mathrm{p}=0.004)$ and occupation $(\mathrm{p}=0.04)$ had a significant association with the attitude and practices towards the COVID-19 pandemic. In conclusion, our study showed that a high level of knowledge, attitude, and practices are the backbone to combat a global crisis like COVID-19.
\end{abstract}

KEYWORDS: comorbidities, COVID-19, India, public health.

\section{INTRODUCTION}

On $31^{\text {st }}$ December 2019, the Wuhan health commission in the Hubei province of The Republic of China alerted the National Health Commission, Chinese Centre for Disease Control and Prevention (CDC), and the World Health Organization (WHO) of an array of 27 patients with pneumonia of unidentified origin [1]. The first reported case was on the $8^{\text {th }}$ December 2019, with most patients either working or living in the neighborhood of Huanan Seafood Market. A peculiar coronavirus (initially termed as 2019-nCoV by WHO) was detected from the patient's throat swab samples on $7^{\text {th }}$ January. The Coronavirus Study Group termed it as severe acute respiratory syndrome coronavirus 2 (SARS-GoV-2), and the WHO framed the term coronavirus disease 2019 (COVID-19) [2].

SARS-CoV-2 is a new public health crisis threatening the world with the emergence and spread of the GOVID-19 infection. WHO affirmed COVID-19 as a pandemic on $11^{\text {th }}$ March 2020 [3]. As of $2^{\text {nd }}$ December 2020, SARS-CoV-2 is reported to have a widespread incidence in 215 countries globally, with a total of 18,338,454 infected cases, 44,754,905 recovered cases, and 1,494,868 deaths [4]. COVID-19 presents with asymptomatic, mild, or severe pneumonia-like symptoms. COVID-19 patients with comorbidities like diabetes, hypertension, renal, respiratory, and cardiovascular disorders, malignancies, HIV, and others are classified as high-risk individuals. They are most susceptible to develop septic shock, acute respiratory distress syndrome, electrolyte imbalances (metabolic acidosis), and coagulation disorders, eventually resulting in the patient's death [5]. 


\section{JOURNAL of MEDICINE and LIFE}

It is well studied now that the SARS-CoV-2 virus utilizes the Angiotensin-converting enzyme 2 (ACE2) receptors found at the surface of the host cells to gain entry inside the cell. Certain comorbidities like hypertension and diabetes are associated with a strong ACE-2 receptor expression and release of increased proprotein convertase levels that encourage the viral entry into the host cells. COVID-19 patients with comorbidities lead a life with a vicious infectious circle and are at increased risk for significant morbidity and mortality rates [5].

Knowing that India is a hotspot of comorbid disorders, including cardiovascular disorders (CVDs), hypertension and diabetes, especially in older people [6]. The case fatality rate or mortality of COVID-19 is linked with the vulnerability and vulnerable groups [7]. The key variables conferring vulnerabilities appear to be age, hypertension, diabetes, chronic heart/lung/renal/hepatic disease states, and many more. Person-to-person transmission (community spread) is currently ongoing in India, making it necessary to control the disease to avoid its rapid spread throughout the country. An effective disease management warrants community compliance for preventive and control actions. This compliance is highly contingent on the population's knowledge, attitudes, and practices (KAP) towards COVID-19. In 2014, Blendon RJ et al. have already shown that the knowledge level and attitudes towards infectious diseases are associated with the level of panic among the population, which can further confound efforts to avert the dissemination of the disease, encouraging alternate management protocols [8].

Hence, it is imperative for the comorbid individual to adopt vigilant preventive measures and undergo scrupulous management. Keeping this in mind, we conducted this study to evaluate the knowledge, attitude, and practice in patients with comorbidities towards the COVID-19 pandemic.

\section{MATERIAL AND METHODS}

This was a cross-sectional online survey carried out among 260 Indian residents. A self-designed structured questionnaire was developed for this study. This structured questionnaire was then converted into Google forms for online data collection. Participants aged 30 years and above and having any comorbid condition were included in the study. At first, the questionnaire was forwarded to authors' known contacts using an email list and Whatsapp contacts with the request to forward it to their known contacts and so on. Informed consent was obtained from each participant before data collection.

The online self-reported questionnaire consisted of five sections to collect demographic details of the participants along with knowledge, attitude about COVID-19, and safe practice measurements during the outbreak. Information about comorbid conditions, duration of comorbidities, and challenges faced by them to manage their comorbid condition during this unpredictable time were also obtained from participants. To get the overall knowledge, attitude, and practice status of participants, each correct/positive response was assigned a value of 1 ; otherwise, the assigned value was 0 . Further, these scores were added to the obtained total KAP scores for each section separately. Total KAP scores were divided into two categories as adequate/positive based on their respective second quartile. Exploratory data analysis was performed to explore the distribution of characteristics under study, and the Chi-square test of association was used to compute the association between categorical variables. Multi-variable binary logistic regression was used to identify factors associated with adequate knowledge. A p-value of less than 0.05 was considered statistically significant. Data were retrieved into Microsoft Excel and analyzed using the IBM SPSS software (IBM SPSS Statistics for Windows, Version 23.0. Armonk, NY: IBM Corp).

\section{RESULTS}

\section{Demographic characteristics of the participants}

A total of 300 participants completed the questionnaire. After excluding 40 respondents who reported to be below 30 years old, the final sample consisted of 260 participants. The majority of the participants were 50 years or older $(50.8 \%)$, predominantly females $(58.5 \%)$. Most of the participants were post-graduates or had their doctorate degree completed $(43.5 \%) .91 .2 \%$ of participants were married, and $41.9 \%$ were working, most of them acquiring a monthly salary of 31,000 Indian rupees (INR) and above (80.9\%). The participants were predominantly suffering from one comorbid condition $(71.5 \%)$ and were diagnosed less than 10 years ago $(73.8 \%)$. The most common comorbidities among the included participants were hypertension, followed by diabetes mellitus and thyroid disorders $(48.5 \%$, $44.7 \%$, and $23.3 \%$, respectively), as shown in Figure 1.

\section{Knowledge, attitude and practice towards COVID-19}

The adequate overall knowledge, attitude, and practice scores of the participants in terms of COVID-19 were $82.7 \%, 75.0 \%$ and $51.2 \%$, respectively, as shown in Table 1 and Figure 2. The knowledge, attitude and practice towards COVID-19 was seen to be adequate among participants aged 50 years or older as compared to less than 50 years old participants $(89.4 \%$ vs. $75.8 \%), 78.8 \%$ vs. $71.1 \%, 51.5 \%$ vs. $50.8 \%$, respectively) (Table 2). Gender-wise, no difference was found concerning knowledge, attitude, and practice about COVID-19. Similarly, we did not find a significant association between KAP and educational status ( $\mathrm{p}=0.052,0.507$ and 


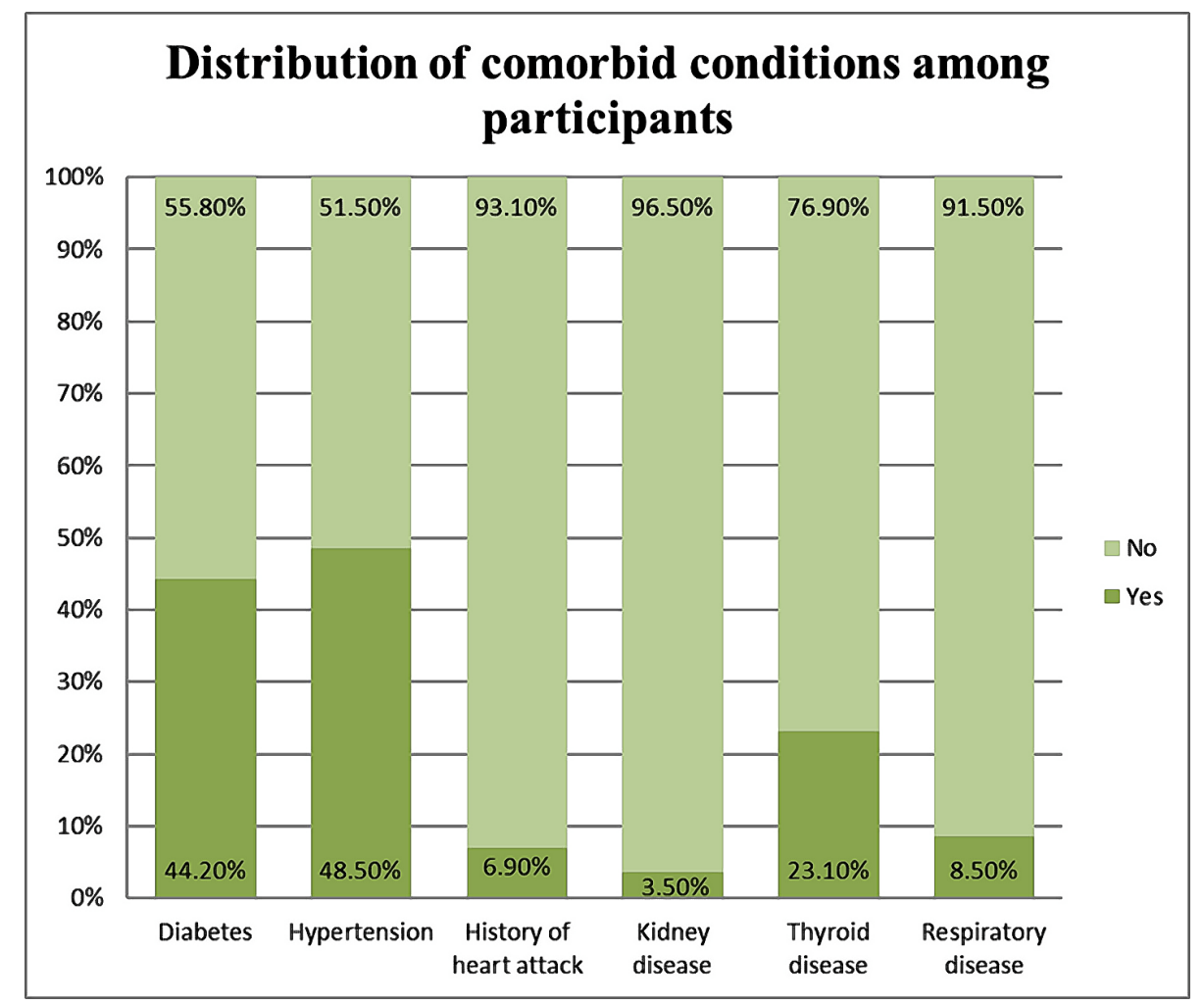

Figure 1. Distribution of comorbid conditions among participants $(\mathrm{n}=260)$.

0.280, respectively for KAP). Participants suffering from more than one comorbid condition $(93.2 \%)$ reported adequate knowledge as compared to those having one comorbid condition $(78.5 \%)$. There was no significant association found based on the duration of diagnosis of the comorbid condition. Among all the participants, diabetic and hypertensive individuals showed better knowledge towards COVID-19 (89.6\% and 88.9\%, respectively). The age of the participants ( $\mathrm{p}=0.011)$, along with the diagnosis of their comorbid con-

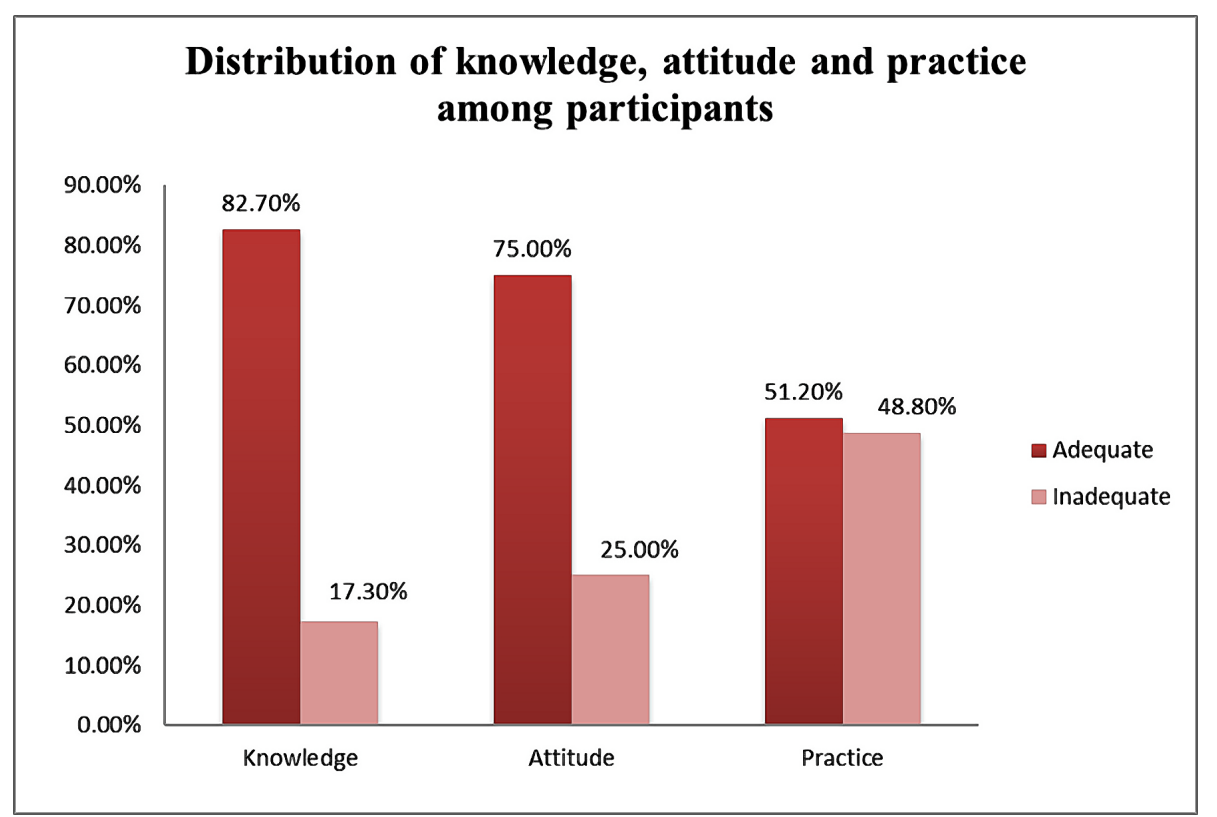




\section{JOURNAL of MEDICINE and LIFE}

Table 1. Frequencies and percentages of knowledge, attitude, and practice about COVID-19 among the participants.

Questions

Preferred Response (\%)

Not preferred Response (\%)

Knowledge-based questions

1. Do you know that your condition is at a high risk for SARS-Cov-2 infection?

$214(82.3)$

46 (17.7)

2. If you and your family are experiencing COVID-19 symptoms, how long should the quarantine period be?

$151(58.1)$

109 (41.9)

Which are the most common symptoms that you need to be aware of as a potential SARS-Cov-2 infection?

$239(91.9)$

4. Do you think that you are preventing COVID-19 transmission by avoiding hand-face-mouth contact?

$237(91.2)$

$23(8.8)$

Atttitude-based questions

5. Do you think the national lockdown due to the COVID-19 pandemic is affecting you and has worsened your condition?

6.

Do you think keeping a positive attitude is the only way to combat the current situation?
Positive attitude (\%)

$131(50.4)$

$205(78.8)$

Which activities do you think are important in preventing COVID-19 transmission?

7.

a) Remove shoes/slippers upon entering homes

b) Clean fruits and vegetables aggressively

c) Keeping groceries in sunlight for at least 4 hours if the lockdown is lifted, will you still maintain social distancing?
$225(86.5)$

35 (13.5)

$226(86.9)$

46 (17.7)

Yes, I will still maintain social

distancing, take all precautions and stay positive.

$217(83.5)$

$214(82.3)$

$$
43 \text { (16.5) }
$$

55 (21.2)

Negative attitude (\%)

129 (49.6)

No, I am tired of this lifestyle, I want things to be back to normal. I feel depressed and lonely and I will visit my friends and family.

\section{Practice-based questions}

9. Are you able to monitor your health during this lockdown due to the COVID-19 pandemic?
Positive practice (\%)

$189(72.7)$
Negative practice (\%)

$71(27.3)$

Are you facing difficulties with the following during the COVID-19 lockdown?

10.

Access to medicines

Access to lab investigations

Access to doctors

How are you protecting yourself from the COVID-19 infection?

Social distancing

General hygiene

11.

$$
\text { Face mask }
$$

Washing hands frequently for $30-40$ seconds

Immune-boosting diet

Regular exercises/yoga/meditation
169 (65.0)

$91(35.0)$

$125(48.1)$

$135(51.9)$

$103(39.6)$

$157(60.4)$ 


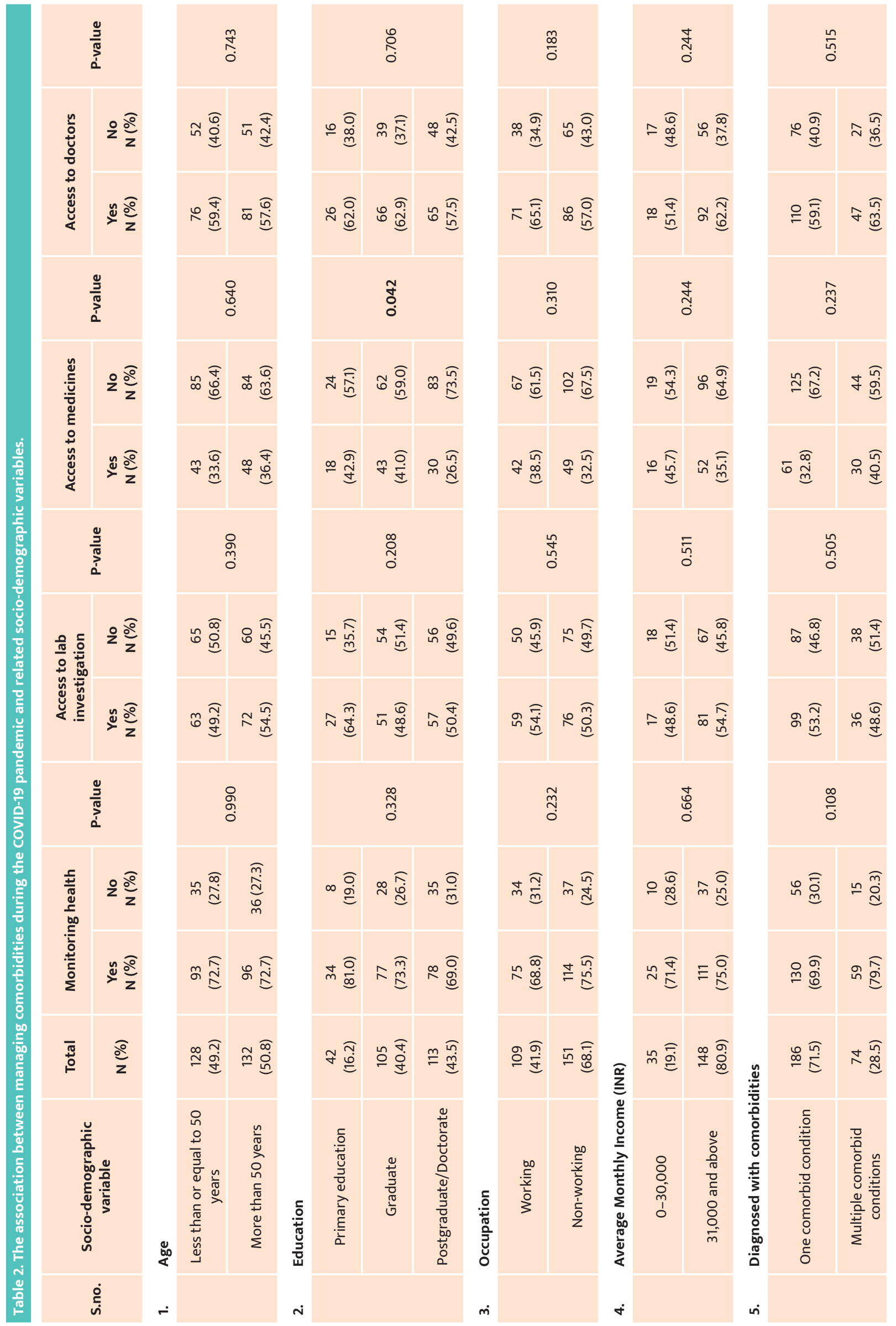


JOURNAL of MEDICINE and LIFE

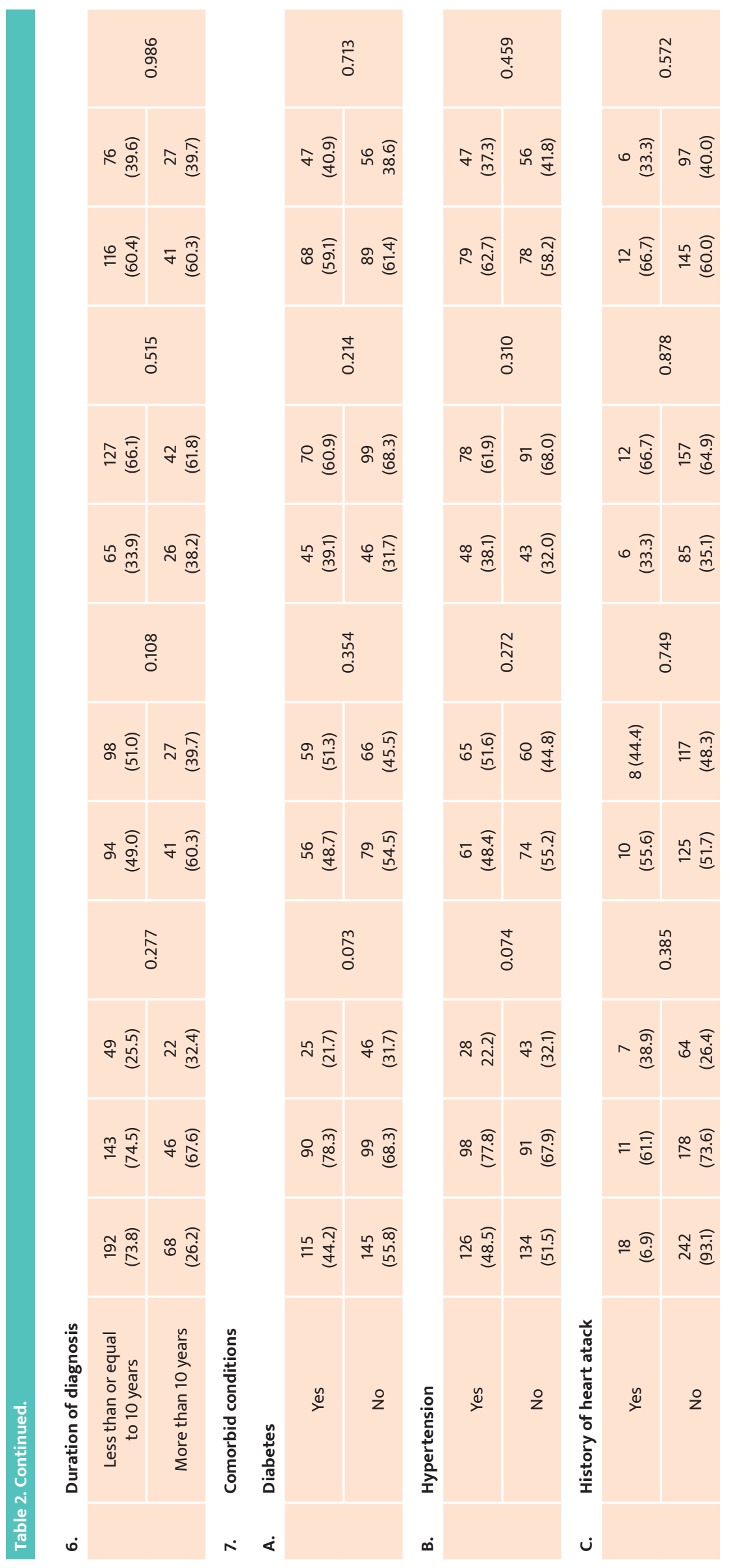




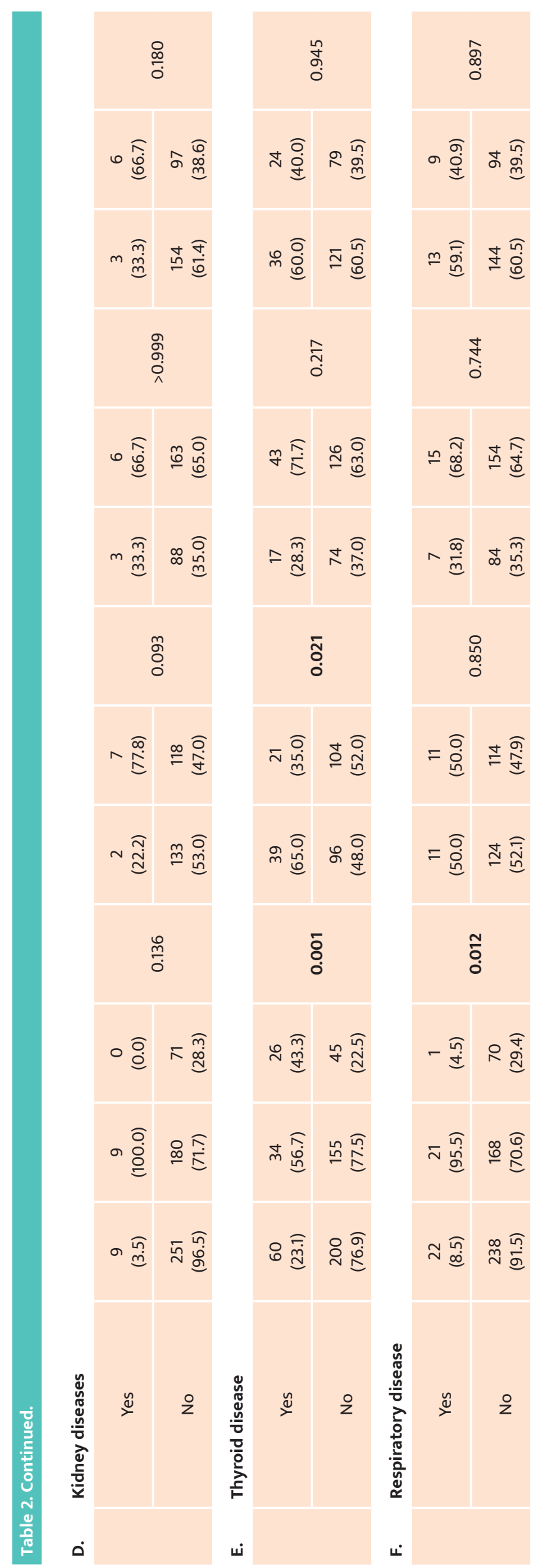




\section{JOURNAL of MEDICINE and LIFE}

ditions $(\mathrm{p}=0.005)$, was found to be significantly associated with the knowledge score. Also, individual comorbid conditions like diabetes $(\mathrm{p}=0.009)$, hypertension $(\mathrm{p}=0.010)$, and thyroid disease $(\mathrm{p}=0.003)$ were significant regarding knowledge towards COVID-19 (Table 2).

\section{Management of comorbidities during COVID-19 pandemic}

The management of comorbidities during COVID-19 is described as shown in Tables 2, 3 and Figure 3. Participants aged 50 years or older reported monitoring their health $(36.9 \%)$ along with difficulty in accessing medicines $(18.5 \%)$. Highly educated participants $(31.9 \%)$ with a monthly income of $31,000 /$ - and above (52.5\%), suffering from multiple comorbid conditions $(16.9 \%)$ with a duration of less than or equal to 10 years $(48.8 \%)$ had difficulty in accessing medicines.

Access to lab investigations and medicines were found to be difficult for diabetic (22.7\%) and hypertensive (25.0) individuals. Accessibility to medicines was significantly associated with the education of the participants (0.042). Also, participants suffering from thyroid diseases (0.001) and respiratory diseases (0.012) were found to be significantly associated with monitoring health and accessibility to lab investigations.

\section{Independent predictors for adequate knowledge}

During bivariate analysis, our study showed that age $(\mathrm{p}=0.005)$ and comorbidities like diabetes $(\mathrm{p}=0.011)$, hypertension $(\mathrm{p}=0.012)$ and thyroid perturbations $(\mathrm{p}=0.004)$ were significantly associated with responders' knowledge. All these factors were analyzed in multivariable settings to identify the independent role of each of these factors after adjusting for these factors. We found that participants older than 50 years were 2.205 (1.072-4.534) times more knowledgeable about the COVID-19 pandemic compared to those participants aged less than or equal to 50 years. Similarly, participants suffering from diabetes and hypertension were found to be associated with more knowledge with an odds of 2.669 (1.187-6.002) and 2.412 (1.058-5.496), respectively, as shown in Table 4.

\section{DISCUSSION}

Currently, the distressingly spread of COVID-19 posed to be a public health emergency across the world. At the moment of writing, no treatment or vaccine that could treat it was discovered. Therefore, prevention is the best solution. Successful prevention and control of COVID-19 are achieved through increasing the population knowledge (especially high-risk groups), attitude, and practice towards COVID-19. To the best of our knowledge, our study is one of the first to examine the knowledge, attitude, and practice variables among individuals with pre-existing comorbidities and their associations with other parameters related to COVID-19. Our study found a high prevalence $(82.7 \%$ ) of adequate knowledge among chronic disease patients. This finding is significantly higher than the results of studies from Ethiopia, Kenya, China, and Iran, where the authors reported a low prevalence of poor knowledge [9-12]. A possible reason for this could be the difference in the socioeconomic status of study respondents. Moreover, it may also be due to the differences in the tools used for calculations. The studies performed in Iran and China were analyzed during the initial phase of the outbreak when most populations had little or no information about COVID-19.

Akwa et al. reported in their study that $>80 \%$ of respondents knew the disease is spread from person to person and by contact with infectious droplets; also, they were aware of the common symptoms [13]. Our findings were in agreement with theirs since $91.9 \%$ of our respondents were well informed. Among all the participants, hypertensive individuals showed better knowledge towards COVID-19 $(43.1 \%)$ even though a positive attitude was seen among all the comorbidities conditions. In our study, women (48.1\%) had an overall better knowledge about COVID 19 compared to men $(34.6 \%)$. Women depicted a predominantly negative attitude towards the COVID-19 pandemic scenario $(60.9 \%)$. This could be because, by nature, women tend to socialize a lot more than men. The social isolation and national lockdown strategies by the government prove to be a hindrance for it. Moreover, $49.60 \%$ of our respondents felt that the national lockdown and social isolation had worsened their existing comorbidities. Most of our respondents have experienced increased anxiety and depression $(23.8 \%$ and $10.40 \%)$, which is similar to another study [14]. However, the levels of anxiety and depression are much lower than those reported by Roy et al., who reported that more than $80 \%$ of their participants experienced anxiety and preoccupation with contracting COVID-19 [15].

During this pandemic, most of our participants had difficulty in maintaining a positive attitude towards life (24.60\%), followed by those who are facing a financial crisis $(20.40 \%$ ). Also, $19.20 \%$ of them faced social isolation, and $19.60 \%$ faced difficulty managing household chores. A possible reason for this could be because most of the respondents in our group were either working from home or were above 50 years of age with house help which was now not the norm. In contrast, many individuals $(27.7 \%)$ were keeping themselves happy by engaging in hobbies and other activities for which they previously had no time.

We also asked our respondents various questions related to the management of their comorbidities. Individuals with thyroid disorders faced significant difficulties in monitoring their condition $(\mathrm{p}$-value $=0.001)$ and had problems accessing a laboratory for frequent testing of thyroid-stimulating hormone (TSH), thyroxine (T4), and triiodothyronine (T3)levels (p-value=0.021). Other comorbidities like diabetes and hypertension were better managed. This can be attributed to increased use of telemedicine and self-monitoring of blood 


\begin{tabular}{|c|c|c|c|c|c|}
\hline 量量 & $\frac{\circ}{\partial}$ & : & శ̊ & : & $\frac{y}{\partial}$ \\
\hline$\frac{2}{2}$ & 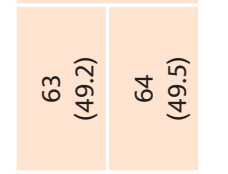 & 政 & 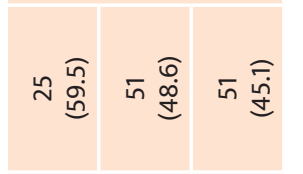 & 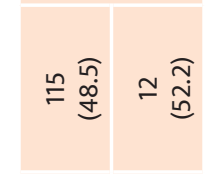 & 路踾 \\
\hline 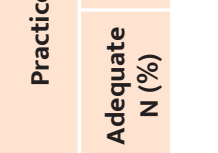 & 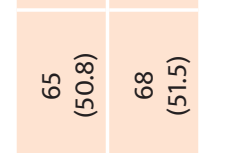 & 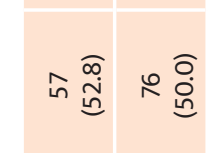 & 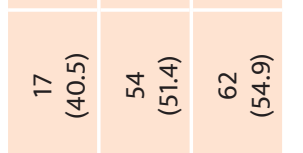 & 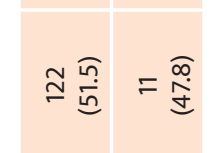 & 揊唔 \\
\hline 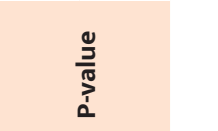 & $\frac{\Omega}{\partial}$ & हू & 高 & ฏ & \\
\hline 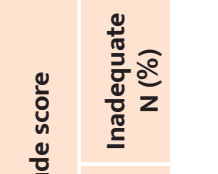 & 동 & 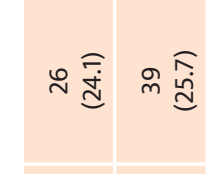 & 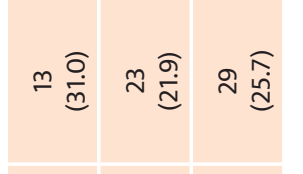 & 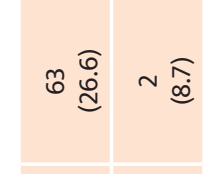 & : \\
\hline 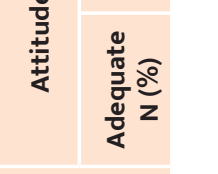 & 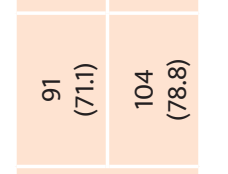 & $x^{2}$ & จำ & 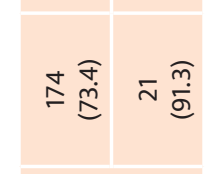 & 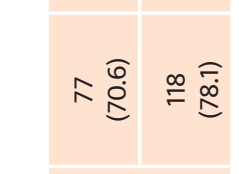 \\
\hline$\frac{1}{1}$ & $\overline{\bar{g}}$ & 善 & 亏ัฐ & $\stackrel{\circ}{\frac{8}{3}}$ & \\
\hline 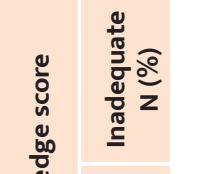 & 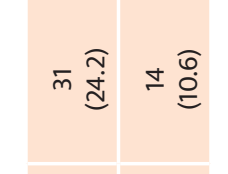 & 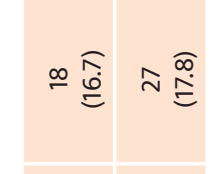 & " & 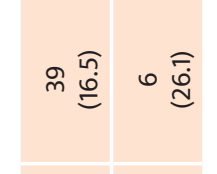 & 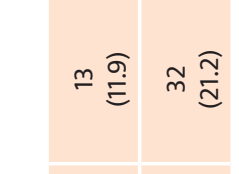 \\
\hline$\frac{1}{10}$ & 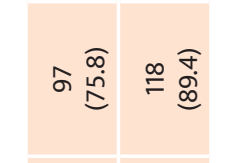 & : & 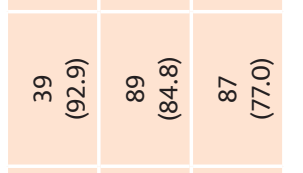 & 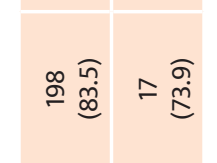 & 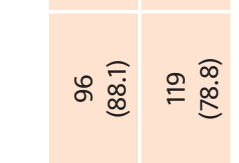 \\
\hline$\frac{\overline{3}}{3}$ & 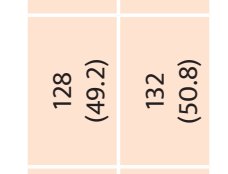 & 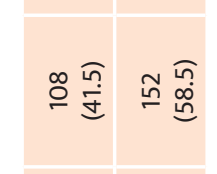 & 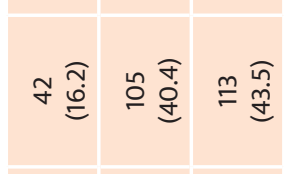 & 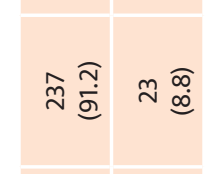 & 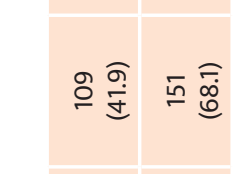 \\
\hline & & &  & $1 /$ & \\
\hline
\end{tabular}




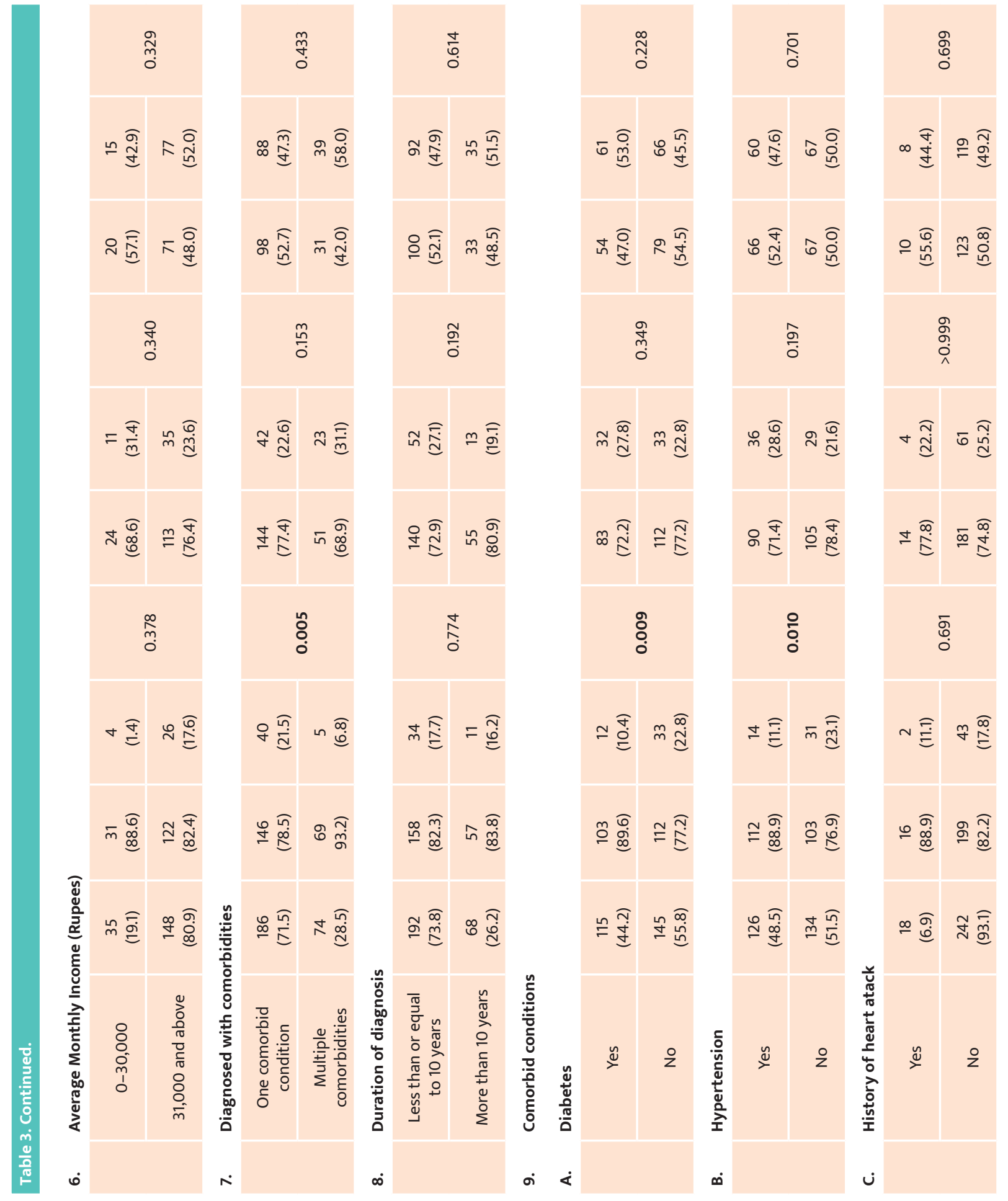




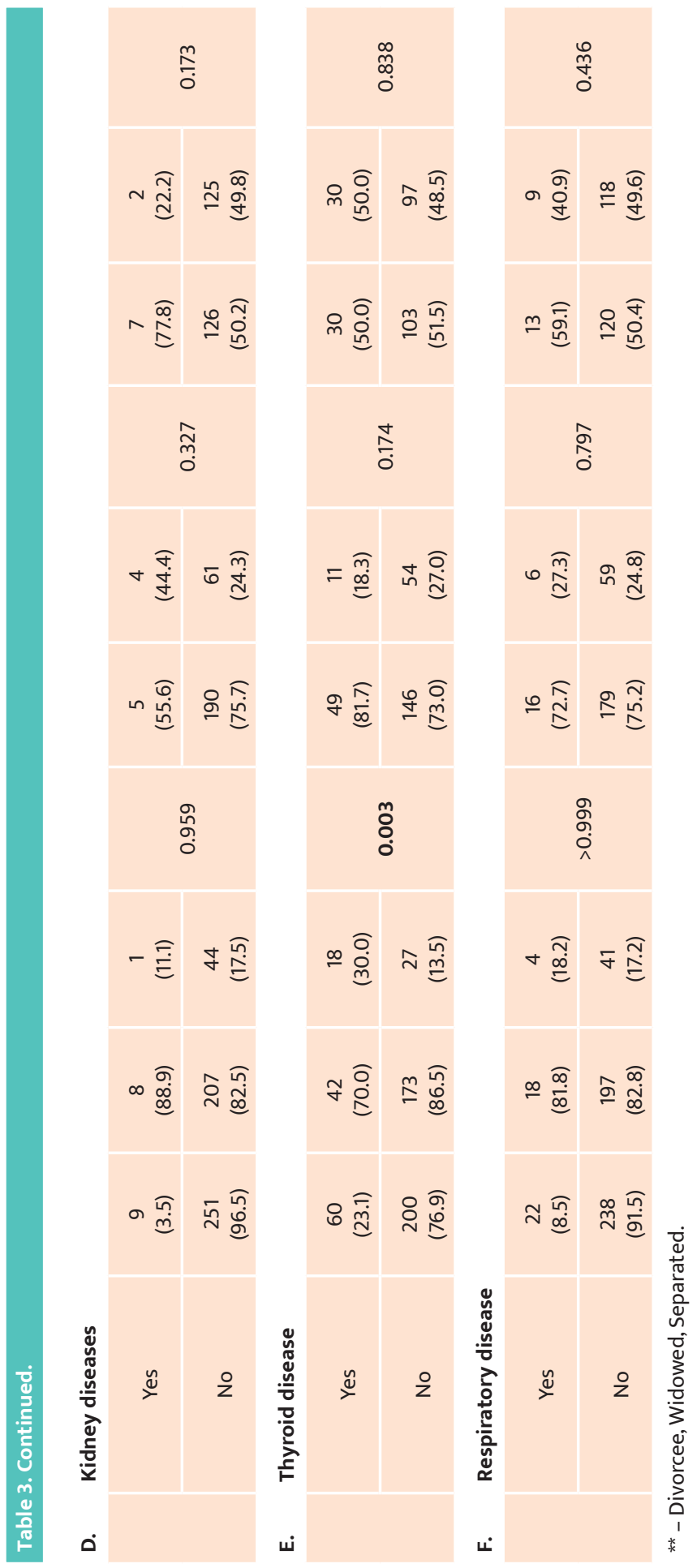




\section{JOURNAL of MEDICINE and LIFE}

Has the lockdown worsened your medical condition?

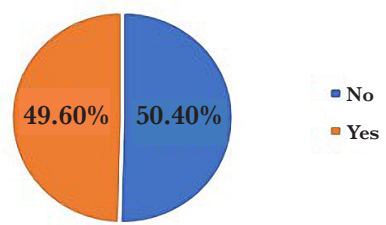

Challenges faced during lockdown

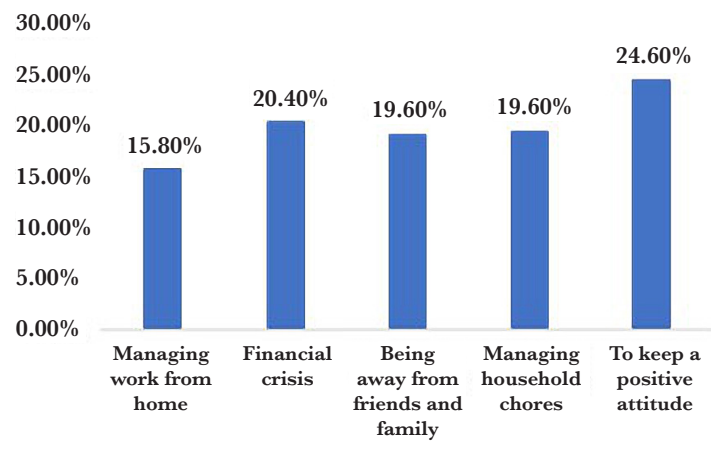

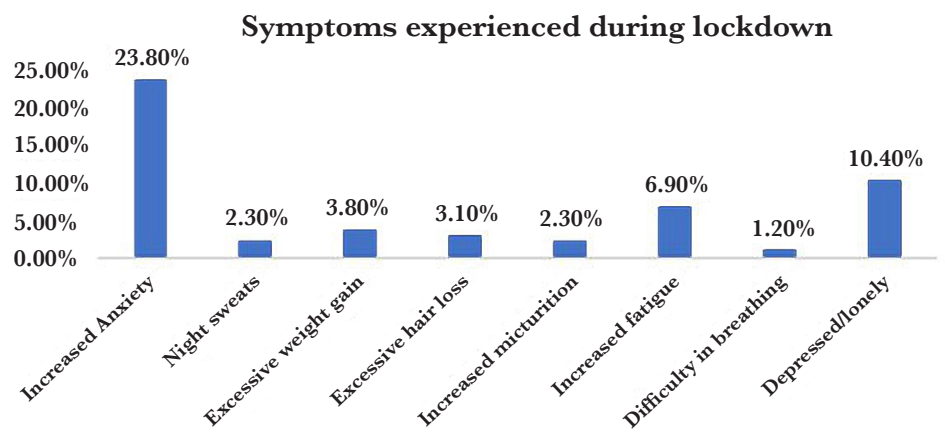

What helps you to cope the social isolation

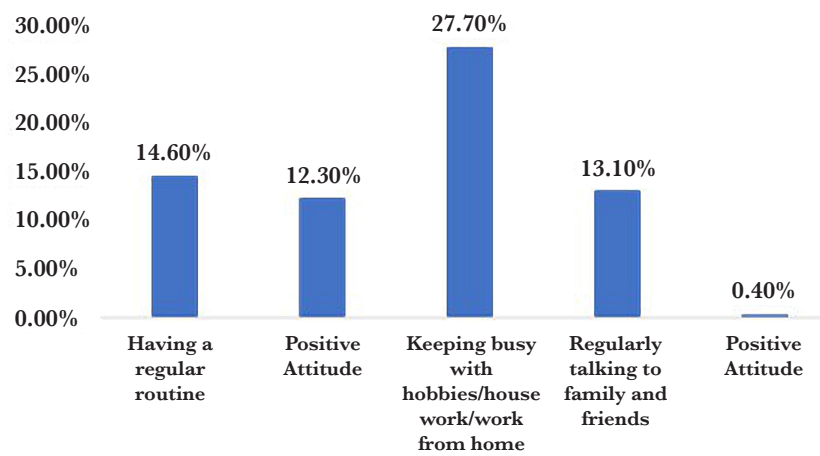

\section{Table 4. Independent predictors for adequate knowledge.}

\begin{tabular}{|c|c|c|c|c|c|c|c|c|c|}
\hline \multirow{3}{*}{ Characteristic } & \multirow{3}{*}{$\begin{array}{c}\text { Number } \\
\text { (\%) }\end{array}$} & \multicolumn{4}{|c|}{ Bivariate } & \multicolumn{4}{|c|}{ Multi-variable } \\
\hline & & \multirow{2}{*}{ Odds Ratio } & \multicolumn{2}{|c|}{ 95\% Cl for Odds Ratio } & \multirow{2}{*}{ P-value } & \multirow{2}{*}{$\operatorname{Exp}(B)$} & \multicolumn{2}{|c|}{ 95\% Cl for Odds Ratio } & \multirow{2}{*}{ P-value } \\
\hline & & & Lower & Upper & & & Lower & Upper & \\
\hline
\end{tabular}

Age

\begin{tabular}{|l|c|c|c|c|c|c|c|}
\hline $\begin{array}{l}\text { Less than or } \\
\text { equal to 50 years }\end{array}$ & $\begin{array}{c}128 \\
(49.2)\end{array}$ & 1.000 & & & & & \\
\hline
\end{tabular}

Diabetes

\begin{tabular}{|l|c|c|c|c|c|c|c|}
\hline & 145 & & & & & \\
\hline No & $(55.8)$ & 1 & & & & & \\
\hline
\end{tabular}

Hypertension

\begin{tabular}{|l|c|c|c|c|c|c|c|c|}
\hline & 134 & & & & \\
\hline No & $(51.5)$ & 1 & & & & \\
\hline
\end{tabular}

Thyroid disorders

\begin{tabular}{|l|c|c|c|c|c|c|c|}
\hline No & $\begin{array}{c}200 \\
(76.9)\end{array}$ & 1 & \\
\hline
\end{tabular}




\section{JOURNAL of MEDICINE and LIFE}

sugar levels. Although the use of smartphone-based consultations has been extensively used during this public health emergency, poor resources like technical glitches, poor quality of audiovisual resources in many parts of India have limited the adequate and satisfactory teleconsultations regarding diabetes education, proper counseling and monitoring of blood pressure.

\section{CONCLUSION}

All available literature and our study hint that individuals with comorbidities face a higher risk of contracting COVID-19. It is well established that the prevalence of diabetes is highest in Indian COVID-19 patients compared to other countries. However, there is a considerable lacuna of knowledge in the published literature on the prevalence of COVID-19 among individuals with comorbidities from India, even though India ranked second worldwide in that aspect. Considering that India has entered the phase of community spread, patients with COVID-19 could be asymptomatic, like many studies from China, Italy, and Kuwait reported. Hence, countries must adopt a strict policy, especially for the high-risk group, for making testing affordable, imposing home quarantine for asymptomatic cases, and above all, social isolation and wearing face masks outdoors.

\section{ACKNOWLEDGMENTS}

\section{Ethical approval}

The approval for this study was obtained from the Ethics Committee of the Amity University, Noida, India (approval ID: AUUP/ IEC/2020-September/04AUUP/IEC/2020-September/04).

\section{Consent to participate}

Informed consent was obtained from the participants and their confidentiality was kept.

\section{Conflict of interest}

The authors declare that there is no conflict of interest.

\section{REFERENCES}

1. Kakodkar, P., Kaka, N. and Baig, M. A Comprehensive Literature Review on the Clinical Presentation, and Management of the Pandemic Coronavirus Disease 2019 (COVID-19). Cureus.2020.

2. Harapan, H., Itoh, N., Yufika, A., Winardi, W., Keam, S., Te, H., Megawati, D., Hayati, Z., Wagner, A. and Mudatsir, M. Coronavirus disease

2019 (COVID-19): A literature review.

Journal of Infection and Public Health.2020;13[5]:667-673.

3. Shahid, Z., Kalayanamitra, R., McClafferty, B., Kepko, D. Ramgobin, D., Patel, R., Aggarwal, C., Vunnam, R., Sahu,

N., Bhatt, D., Jones, K., Golamari, R. and Jain, R. COVID

-19 and Older Adults: What We Know. Journal of the American Geriatrics Society.2020;68[5]:926-929.

4. Worldometers.info. 2020. Coronavirus Update (Live): 29,189,557 Cases And 928,333 Deaths From COVID-19 Virus Pandemic - Worldometer. [online] Available at: <https://www.worldometers.info/coronavirus/> [Accessed 14 September 2020]

5. Ejaz, H., Alsrhani, A., Zafar, A., Javed, H., Junaid, K., Abdalla, A., Abosalif, K., Ahmed, Z. and Younas, S. COVID-19 and comorbidities: Deleterious impact on infected patients. Journal of Infection and Public Health. 2020.

6.Dey JK, Dey SK. SARS-CoV-2 Pandemic, COVID-19 Case Fatality Rates and Deaths per Million Population in India. J Bioinf Com Sys Bio. 2020; 2[1]: 110
7. World Health Organization. 2020. Pneumonia of Unknown Cause - China,5 January.https://www.who.int/ csr/don/05-january-2020-pneumonia-of-unkown-causechina/en

8. Blendon, R., Benson, J., DesRoches, C., Raleigh, E. and Taylor-Clark, K.The Public's Response to Severe Acute Respiratory Syndrome in Toronto and the United States. Clinical Infectious Diseases. 2004;38[7]:925-931.

9. Kebede, Y., Yitayih, Y., Birhanu, Z., Mekonen, S. and Ambelu, A. Knowledge, perceptions and preventive practices towards COVID-19 early in the outbreak among Jimma. university medical center visitors, Southwest Ethiopia. PLOS ONE, 2020;15[5]:0233744

10. Zhong, B., Luo, W., Li, H., Zhang, Q., Liu, X., Li, W. and $\mathrm{Li}, \mathrm{Y}$. Knowledge, attitudes, and practices towards COVID-19 among Chinese residents during the rapid rise period of the COVID-19 outbreak: a quick online crossperiod of the COVID-19 outbreak: a quick online cross-
sectional survey. International Journal of Biological Sciences. 2020 $20 ; 16[10]: 1745-1752$.

11. Erfani A, Shahriarirad R, Ranjbar K.,2020. Knowledge, attitude and practice toward the novel coronavirus (COVID-19) outbreak: a population-based survey in Iran. Bull World Heal Organ. 2020;(3).
12. Taghrir, M., Borazjani, R. and Shiraly, R. COVID-19 and Iranian Medical Students; A Survey on Their RelatedKnowledge, Preventive Behaviors and Risk Perception Archives of Iranian Medicine. 2020; 23[4]:249-254.

13. Akwa, T., Muthini, M. and Ning, T. Assessing the Perceptions and Awareness of COVID-19 (Coronavirus) in Cameroon. SSRN Electronic Journal. 2020.

14. Rajkumar, R. COVID-19 and mental health: A review of the existing literature. Asian Journal of Psychiatry. 2020;52:102066.

15. Roy, D., Tripathy, S., Kar, S., Sharma, N., Verma, S. and Kaushal, V. Study of knowledge, attitude, anxiety \& perceived mental healthcare need in Indian population. during COVID-19 pandemic. Asian Journal of Psychiatry. 2020; $51: 102083$. 